\title{
Kinetics of adsorption of iron ions (III) by natural zeolite
}

\author{
Vira Sabadash, Jaroslaw Gumnitsky \\ Department of Ecology and Sustainable Environmental Management, Lviv Polytechnic National University, \\ UKRAINE, Lviv, 12, S.Bandery St., 79013, E-mail: virasabadash @ gmail.com
}

\begin{abstract}
The natural zeolite was used as adsorbent for Fe(III) removal from aqueous solution. The maximum adsorption capacity was $309.5 \mathrm{mg} \mathrm{Fe} \mathrm{F}^{3+} / \mathrm{g}$ zeolite. The kinetic data were fitted to homogeneous micropore model and found that the mass transfer coefficient and diffusivity of the $\mathrm{Fe}^{2+}$ are directly affected by the kinetic parameters.
\end{abstract}

Keywords - adsorption, masstransfer, kinetis, heavy metals, zeolite

\section{Introduction}

In the present work, application of natural zeolite was investigated for removal of heavy metals from water. Particularly for removal of iron ions from aqueous solution as a major contaminant that enters water by corrosion of household plumbing systems. The adsorption capacity of zeolite relative to heavy metal ions depends on the radius of the ion and its charge in the order $\mathrm{Pb}$ (II) $>\mathrm{Cr}(\mathrm{VI})>\mathrm{Cu}$ (II) $>\mathrm{Cr}$ (III) $>\mathrm{Zn}$ (II). Atom radii: $\mathrm{Pb}$ (II) $147 \mathrm{pm}(120 \mathrm{pm})>\mathrm{Cu}$ (II) $138 \mathrm{pm}(96 \mathrm{pm})>\mathrm{Zn}$ (II) $131 \mathrm{pm}(74 \mathrm{pm})>\mathrm{Cr} 127 \mathrm{pm}$ (III) $(65 \mathrm{pm})>\mathrm{Cr}$ (VI) (52 pm) ) and electronegativity by Pauling: $\mathrm{Pb}$ (II) (2.33)> $\mathrm{Cu}$ (II) (1.9) $>\mathrm{Cr}$ (VI) $>$ (1.66) $\mathrm{Cr}$ (III) (1.66) $\mathrm{Zn}$ (II) (1.65). Thus, the adsorption capacity of zeolite relative to heavy metal ions depends on the ion radius and valence of the metal in the corresponding compound. Multicharged ions are best absorbed. The effects of adsorption kinetic parameters were tested in order to obtain the optimum kinetic parameter for minimizing the rate of adsorption of iron.

\section{Experimental}

Aqueous solutions of iron chloride of initial concentrations ranging from 10 to 500 $\mathrm{mg} / \mathrm{dm}^{3}$ were prepared. Batch adsorption isotherms were performed for fixed particle size of zeolite $(<3 \mathrm{~mm})$. Using two sets of stopper bottles, equal weights of $0.1 \mathrm{~g}$ of the produced zeolite were added to $0.1 \mathrm{dm}^{3}$ of $\mathrm{Fe}^{3+}$ solution. Then the zeolite/ $\mathrm{Fe}^{3+}$ mixtures were placed in an isothermal shaker $\left(20 \pm 1{ }^{\circ} \mathrm{C}\right)$ for 2 days to allow complete equilibration. Based on different nature of acidity of the produced zeolite, $\mathrm{pH}$ was adjusted by adding few drops of $\mathrm{NaOH}$ or $\mathrm{HCl}$. Batch adsorption kinetic studies were performed in a $1 \mathrm{dm}^{3}$ beaker with Plexiglas cover. This cover is attached with 4 Plexiglas baffles spaced around the circumference at $90^{\circ}$ to ensure smooth mixing without stagnant areas and vortex formation. Mixing was carried out using a twoblade stainless steel impeller driven by a variable speed motor. The experiments were established by adding a fixed weight of the produced zeolite into $0.5 \mathrm{dm}^{3}$ of known $\mathrm{Fe}^{3+}$ solution, and kept agitated for $180 \mathrm{~min}$. All experiments were carried out at ambient temperature $(20 \pm 1 \circ \mathrm{C})$ unless otherwise stated. Effect of stirring speed (200, 400 and $800 \mathrm{rpm}$ ) was also considered in the kinetic experiments. Samples were withdrawn at time interval of 0.5, 1, 2, 3, 5, 10, 20, 30 and 60 min using a fritted glass tube then centrifuged to remove the suspended particles. The resulting samples were analyzed using Thermo Element Atomic Absorption Spectrophotometer.

A graphical interpretation of the experimental data on the adsorption of iron with natural zeolite by the Langmuir isotherm for the area of initial concentrations up to $500 \mathrm{mg} / \mathrm{dm}^{3}$ is presented on Fig. 1. 
$a^{*}$

$\mathrm{mg}-\mathrm{eq} / \mathrm{g} \cdot \mathrm{ads}$

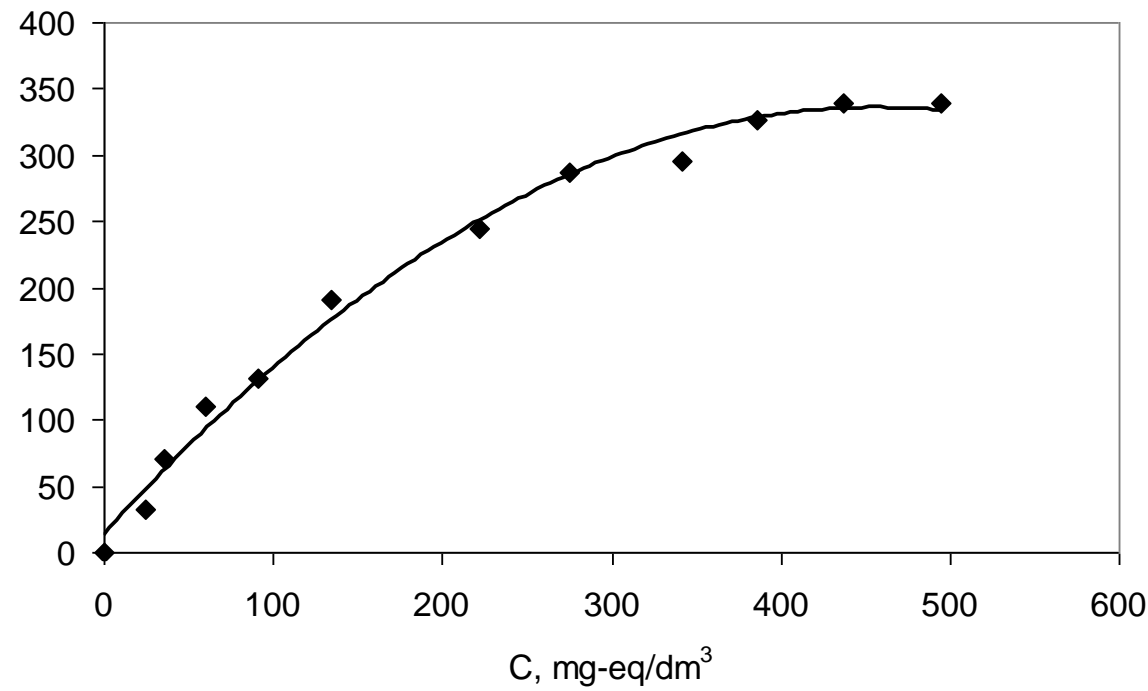

Fig. 1 - Isotherm for adsorption of Fe(III) by natural zeolite

For the experimental conditions, a diagram of the distribution of concentrations of the products of the interaction of iron chloride with aluminosilicate was ploted (Fig. 2). To obtain the calculated dependences, it was taken into account that the studied zeolite contains $\mathrm{Al}_{2} \mathrm{O}_{3}$ and $\mathrm{SiO}_{2}$ in a ratio of 1: 6.

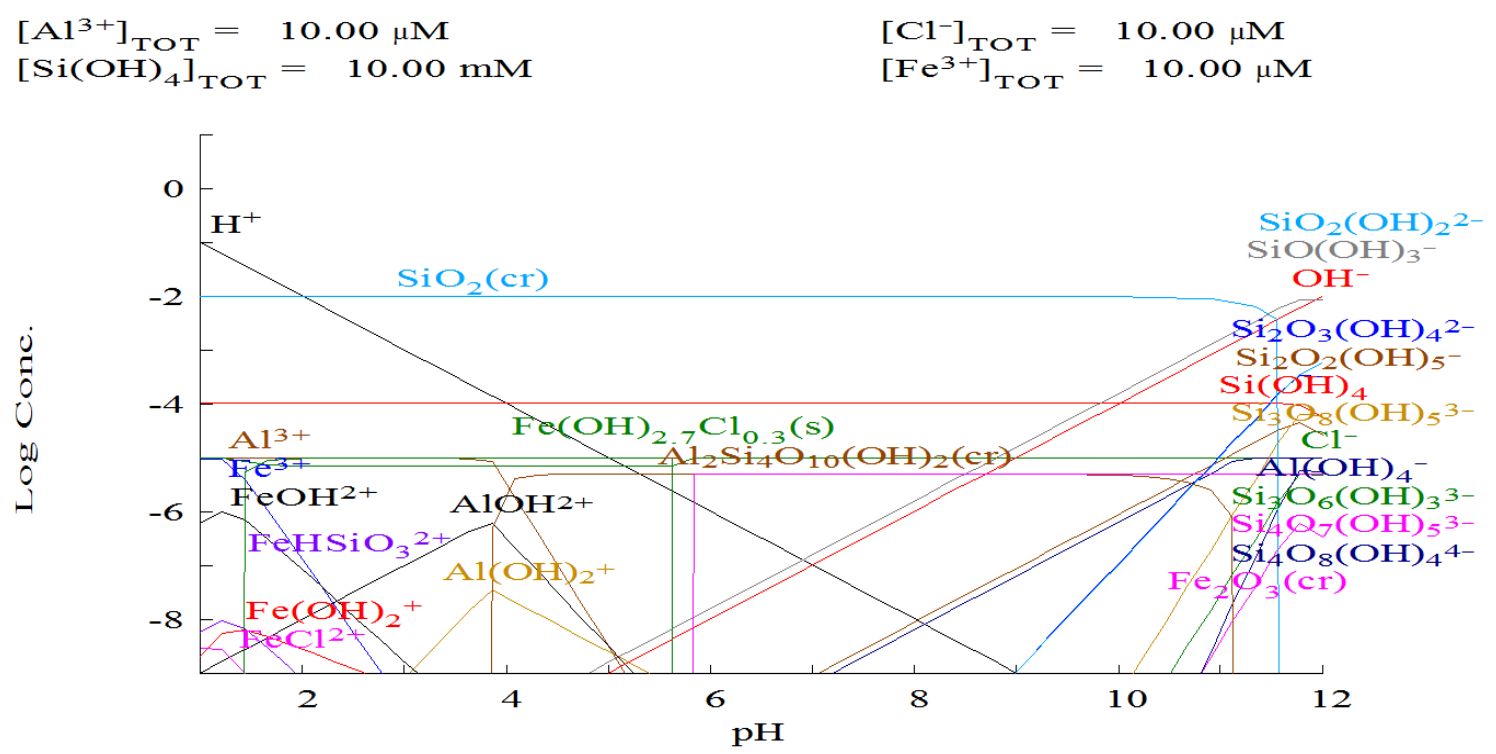

Fig. 2 - The approximate composition of the products of the interaction of $\mathrm{FeCl}_{3}$ with zeolite depending on the $\mathrm{pH}$

Therefore, in addition to ion exchange in the adsorption system is quite an incredible phenomenon of chemisorptions. The results of the study of adsorption kinetics are presented in Fig. 3. Agitation speeds were carried out at 200, 400, 600 and $800 \mathrm{rpm}$. 


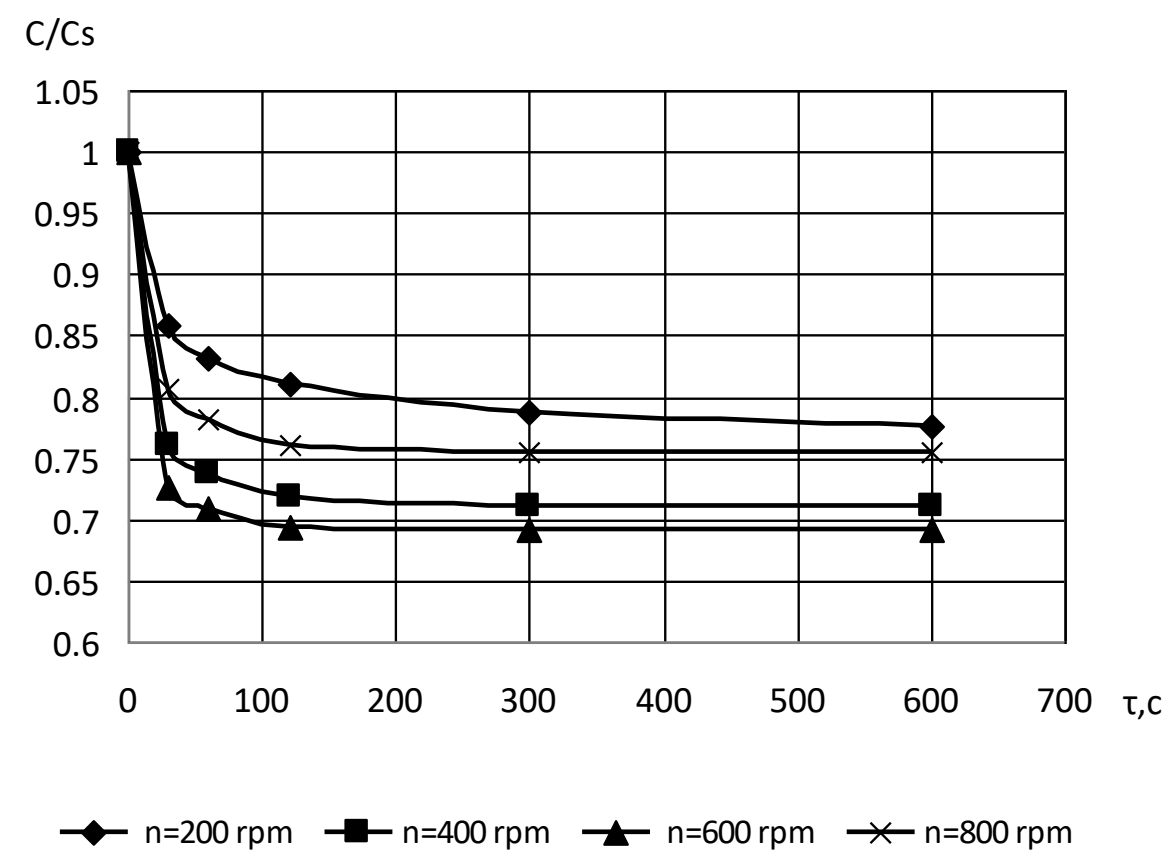

Fig. 3 - Effect of agitation speed on the adsorption kinetics Fe(III) of by natural zeolite Table 1 - Adsorption kinetic parameters for removal of Fe(III) from aqueous solution.

\begin{tabular}{|c|c|c|}
\hline Mixing speed,rpm & Values $\beta(\mathrm{cm} / \mathrm{s})$ & Deff $(\mathrm{cm} 2 / \mathrm{s})$ \\
\hline 200 & 0.001 & $4.01 \times 10-6$ \\
400 & 0.005 & $5.77 \times 10-6$ \\
600 & 0.0057 & $7.01 \times 10-6$ \\
800 & 0.0063 & $9.05 \times 10-6$ \\
\hline
\end{tabular}

It appears that the increase in speed of agitation decreased the time required for iron to equilibrate. This increase in agitation speed decreased the boundary layer resistance to mass transfer, increased the diffusion rate of Fe(III) from the bulk into zeolite particles and hence increased in the rate of iron uptake. Moreover, the number of collisions between Fe(III) ions inside the micropores will increase leading to the increase in diffusion coefficient which increase the rate of adsorption.

\section{Conclusion}

The adsorption isotherm and kinetics data obtained for the removal of copper ions from aqueous solution would be perfectly attained by the natural zeolite of Sokyrnytsia deposit. The adsorption is affected by the concentration of Fe(III) where an increase in adsorption capacity is cleared with the increase in initial concentration. The kinetic parameters showed that the rate of adsorption is well enhanced with agitation speed. The provided model best fitted to the experimental data and predicted the variation of particles porosity on the removal efficiency. The given adsorbent is not expensive, widely available and solve an environmental issue.

\section{References}

[1] Sabadash, V., Mylanyk, O., Matsuska, O., \& Gumnitsky, J. (2017). Kinetic regularities of copper ions adsorption by natural zeolite. Chemistry \& Chemical Technology, 4 (11), 2017, 11(4), 459-462.

[2] Hyvlud, A., Sabadash, V., Gumnitsky, J., \& Ripak, N. (2019). Statics and kinetics of albumin adsorption by natural zeolite. Chemistry \& Chemical Technology, 1 (13), 2019, (1), 95-100. 